\title{
Cerebral oxygen saturation monitoring during spinal neurosurgery in prone position using near infrared spectroscopy (NIRS)
}

Murniece S. ${ }^{1,2}$, Skudre A. ${ }^{1,2}$, Stepanovs J..$^{1,2}$, Vjugins J. ${ }^{1,}$,Vanags I. ${ }^{2}$, Mamaja B..$^{1,2}$

${ }^{1}$ Riga East University Hospital, Latvia

${ }^{2}$ Riga Stradins University

\section{BACKGROUND}

- NIRS used intraoperatively can prevent posto perative complication s like cognitive dysfunction and organ failure.

- The goal of the study was to determine whether prone position during spina 1 neuros urgery impacts cerebral oxygen saturation using NIRS.

\section{METHODS}

- 28 patients (mean age 56y) were scheduled for spinal surgery in prone position (transpedicular fixation( $\mathrm{TPF})=15$, microdiscectomy $(\mathrm{MDE})=8$, sp inal tumor $\operatorname{removal}(\operatorname{spinal} \mathrm{Tu})=4$, laminectomia=1).

- Cerebral oxygen saturation $(\mathrm{rScO} 2)$ was continuously monitored using INVOS 4100.

- We also assessed blood loss, postoperative complications (stroke, organ dysfunction, wound infection, days spent in ICU) and cognitive dysfunction.

- Anesthesia metho ds: induction with fentany 1 0.1-0.2 mg, pr opofol 1$2 \mathrm{mg} / \mathrm{kg}$, atracurium $0.5 \mathrm{mg} / \mathrm{kg}$; maintenance - fentanyl 0.03 $0.06 \mu \mathrm{g} / \mathrm{kg} / \mathrm{min}$, atracurium $0.3-0.6 \mathrm{mg} / \mathrm{kg} / \mathrm{h}$, sevoflurane to MAC $0.7-1.0, \mathrm{FiO} 20.5$

- All patients were extubated in the operating room.

\section{RESULTS}

- Significant changes in calculated mean $\mathrm{rScO} 2$ values between supine and prone position during the surgery were not observed (Figure 1).

- Mean $\mathrm{rScO} 2$ during the whole surgery was $73 \%$ for the right side (R), 73\% for the left side (L). Lying supine during induction R72\%, $\mathrm{L} 71 \%$, in prone position $\mathrm{R} 74 \%$, $\mathrm{L} 74 \%$, returning back to spinal position $\mathrm{R} 73 \%$, $\mathrm{L} 73 \%$.

- 11 out of 28 patients showed a slight to significant decrease in $\mathrm{rScO} 2$ values in prone position (Figure 2).

- One patient with intraoperative blood loss $(2000 \mathrm{ml})$ showed a $\mathrm{rScO} 2$ decrease by $27 \%$ from baseline value (from r ScO2 $85 \%$ to $58 \%$ in prone position).

- One patient with stroke in anamnes is showed initial va lues before induction of anaesthesia $21 \%$ lower than average $\mathrm{rScO} 2 \quad(57 \%$ compared to average $\mathrm{rScO} 272 \%$ ).

- Average blood loss was $308 \mathrm{ml}$ ( $\mathrm{TPF}=400 \mathrm{ml}$; $\mathrm{MDE}=175 \mathrm{ml}$; spinal $\mathrm{Tu}=200 \mathrm{ml})$.

- Average duration of operation was $110 \mathrm{~min} \quad(\mathrm{TPF}=112 \mathrm{~min}$; $\mathrm{MDE}=125 \mathrm{~min}$; spinal $\mathrm{Tu}=126 \mathrm{~min}$ ).

- No incidence of stroke, organ dysfunction was observed. One patient was admitted to ICU due to blood loss.
Figure 1. Mean $\mathrm{rScO}_{2}(\%)$ values - supine and prone position (Supine1 - supine position during induction of anaesthesia; Supine 2 - supine position at the end of the operation)

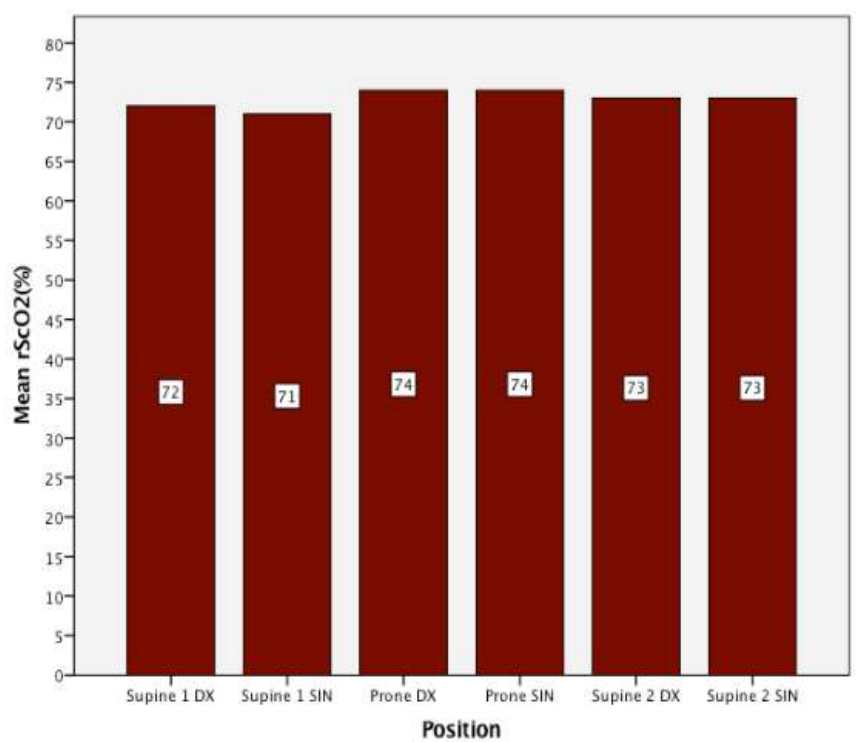

Figure 2. Mean in traoperative $\mathrm{rScO}_{2}(\%)$ decrease in prone position from baseline values observed in 11 patients

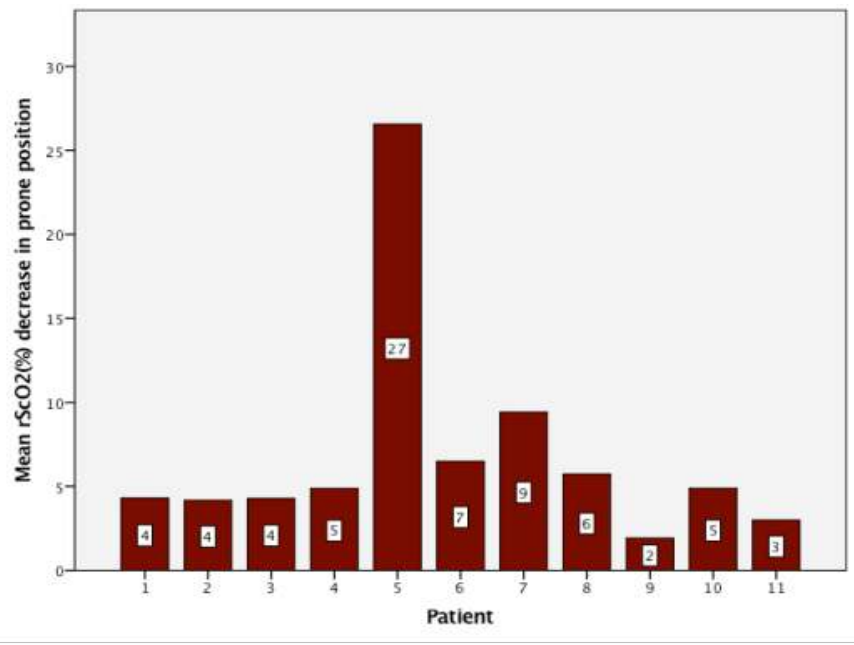

\section{CONCLUSION}

- Our first experience revealed, that the mean intraoperative cerebral oxygen saturation changes, during spinal neurosurgery, were not significant.

- 11 out of 28 patients showed a mild to moderate decrease in cerebral oxygen saturation in prone position. 